\title{
Experiments and numerical modeling of baffle configuration effects on the performance of sedimentation tanks
}

\author{
A.M. Razmi ${ }^{\text {a*}}$, R. Bakhtyar ${ }^{\text {a,b }}$, B. Firoozabadi ${ }^{c}$, and D.A. Barry ${ }^{\text {a }}$ \\ ${ }^{\mathrm{a}}$ Laboratoire de technologie écologique, Institut d'ingénierie de l'environnement, Faculté de l'environnement naturel, architectural et \\ construit (ENAC), Station 2, Ecole polytechnique fédérale de Lausanne (EPFL), 1015 Lausanne, Switzerland. Emails: \\ $\underline{\text { amir.razmi@epfl.ch, }} \underline{\text { roham.bakhtyar@epfl.ch, andrew.barry@epfl.ch }}$ \\ b Now at: Department of Environmental Sciences and Engineering, The University of North Carolina, Chapel Hill, NC 27599-7431, USA \\ ${ }^{\mathrm{c}}$ School of Mechanical Engineering, Sharif University of Technology, Azadi Avenue, Tehran, Iran. Email: firoozabadi@ sharif.edu
}

Published in: Canadian Journal of Civil Engineering, 2013

${ }^{*}$ Author to whom all correspondence should be addressed. Tel: +41 (21) 693-5793; Fax. +41 (21) 693-8035 
Abstract: The hydraulic efficiency of sedimentation basins is reduced by short-circuiting, circulation zones and bottom particle-laden jets. Baffles are used to improve sediment tank performance. In this study, laboratory experiments were used to examine the hydrodynamics of several baffle configurations. An accompanying numerical analysis was performed based on the 2D ReynoldsAveraged Navier-Stokes equations along with the $k$ - $\varepsilon$ turbulence closure model. The numerical model was supplemented with the Volume-Of-Fluid technique (VOF), and the advection-diffusion equation to simulate the dynamics of particle-laden flow. Model predictions compared well with the experimental data. An empirical function was constructed to indicate the location and amount of sediment collected in the tank. Hydraulic performance was determined for given baffle locations and heights. The results revealed that, for the laboratory setup, a baffle half way along its length decreases its performance, while a baffle much closer to its inlet and with height $25 \sim 30 \%$ of water depth improves efficiency.

Keywords: Baffled tank; Drinking water settling tank; Hydraulic removal performance; Hydrodynamics; Sedimentation; Particle-laden flow; Turbulent flow 


\section{Introduction}

Sedimentation tanks are important components of any water purification plant, and account for approximately a third of the infrastructure cost (Tamayol et al., 2008). Their task is to remove suspended particles from the flow field, so their efficiency affects the performance of other parts of the plant (Ekama et al., 1997).

Sedimentation Tank (ST) usage can be classed into two main categories: (i) Waste-Water Treatment Plants (WWTPs) and (ii) Water Treatment Plants (WTPs). WWTPs include Primary (PSTs) and Secondary Settling Tanks (SSTs). PSTs are designed to dissipate kinetic energy, reduce the overall flow velocity and to let solids settle (Goula et al., 2008). Typically, SSTs are located after mixers in WWTPs, where flocculation and coagulation processes occur (Kleine, 2005). Flocculation can also take place in the SST's influent pipes. Modern WTPs typically contain one ST (Technical Guidelines for the Construction and Management of Drinking Water Treatment Plant, 2009). STs can be divided into two main types: rectangular and circular (Smethurst, 1992; Wang et al., 2011). Rectangular STs, considered here, are easily designed and have some advantages such as lower construction cost and efficient space utilization. For such tanks, the influent particle concentration is low, and sludge flow is negligible in comparison to the influent flow and can be ignored (Lawler and Benjamin, 2011).

In terms of their internal functioning, STs can be divided into four areas: (i) inlet zone, (ii) settling zone, (iii) sludge zone, and (iv) outlet zone (Manual on Water Supply and Treatment, 1999). At the tank exit, the Solids Loading (SL, solids flux in the outflow, Parker et al., 2001) is the design parameter that defines the tank's capacity. Sediment deposition, and thus tank efficiency, is a function of energy dissipation in the tank, which is in turn related to maximal flow rates. Probably the least efficient ST is one in which a jet formed at the inlet is routed directly to the tank exit without appreciably lowering its 
inlet (i.e., maximum) velocity. This pattern would, additionally, induce circulations that would maintain sediments in suspension. These "dead" zones decrease the tank's effective volume, and decrease tank performance if they are accompanied by intense mixing and turbulence leading to sediment resuspension (e.g., Krebs et al., 1996). An ideal tank would induce a relatively uniform (low) flow rate, allowing maximal sedimentation (and hence minimal SL). However, since tanks have relatively small entrance and exit weirs, non-ideal regions with high circulation usually exist (American Water Works Association, 1990; Yoon and Lee, 2000). Baffles can interrupt short-circuiting, giving rise to a modified flow field and, potentially, improved the tank performance. However, prediction of the effect of baffles is a challenging numerical simulation problem. More generally, since ST performance is influenced directly by the flow structure (Ahmed et al., 1996), investigation of their hydraulic phenomena using validated numerical models can help improve ST design.

For rectangular settling tanks with large length-to-width ratios, three-dimensional flow regions are limited to small areas near the walls if the inlet and exit openings span the tank's width (e.g., Lyn et al., 1992; Stamou et al., 2009; Tamayol et al., 2011). This situation, considered in this study, can be simulated using a 2D numerical model.

There are a number of comprehensive studies on baffled tanks that investigate their hydraulic efficiency (McCorquodale and Zhou, 1993; Tamayol et al., 2010; Xanthos et al., 2010). Brescher et al. (1992) considered a rectangular clarifier and showed that an intermediate (where intermediate refers to location along the tank length) baffle on the base of the tank, transverse to the main flow direction, influences the flow field and can improve efficiency. Krebs $(1991,1995)$ focused on the flow field and the potential energy of incoming flows. His analysis was based on a 2D hydrodynamics code validated by laboratory results. The model was applied to evaluate various inlet arrangements and bottom currents. To enhance sediment settlement on the tank bottom, he suggested placement of an inlet baffle. Numerical models of flow patterns, sediment mixing rate and turbulence characteristics in STs have 
been reported. Celik et al. (1985) and Adams and Rodi (1990) used the $k-\varepsilon$ turbulence closure model. Lyn et al. (1992) showed that the flow field depends on the particle density entering the tank and the entrance geometry.

Tamayol et al. (2008) examined the tank performance using the particle-tracking method. They observed a large circulation zone and concluded that a baffle placement that disturbed this zone resulted in improved tank performance. Goula et al. (2008) indicated that the baffle height is important, as it can decrease the inlet recirculation zone and increase sedimentation. Liu et al. (2010) used laser Doppler velocimetry to conduct flow-field measurements, accompanied by numerical simulation of the flow field to evaluate the effect of inlet height on sedimentation efficiency. Effects of baffle height and position were not considered. The effect of baffle angles and position were examined using a $2 \mathrm{D}$ model (Flow-3D, 2003) applied to a small-scale, 2-m long laboratory setup (Rostami et al., 2011; Shahrokhi et al., 2011, 2012). Right-angled (to the tank base) baffles were most favourable for sedimentation. In addition, it was concluded that, to get high settling performance, the baffle should be somewhere close to the inlet. However the effects of baffle height and optimal baffle configuration were not considered.

The combination of the hydrodynamic and sediment transport equations plays an important role in numerical modeling of STs. While models of physical processes in STs have been reported (e.g., Stamou et al. 2010), we suggest that comprehensive numerical models that incorporate a suitable turbulence closure model, sediment concentration and appropriate free surface tracking technique are valuable to quantify the hydrodynamics of baffled tanks. Table 1 summarizes previous studies on baffled tanks and highlights their characteristics. Numerical and experimental studies that consider in detail the effect of baffle positions on ST efficiency and determine the optimal position and height of baffle have yet to be reported. 
Razmi et al. (2009) used a two-dimensional, two-phase air-water model (FLUENT, 2003) to simulate primary ST hydrodynamics. The model was used to investigate effects of a baffle on the flow field. ST hydrodynamics were simulated using the unsteady Eulerian-Eulerian finite volume method in conjunction with a RNG turbulence closure model and the Volume-Of-Fluid (VOF) model. For model validation, laboratory velocity-profile data from a rectangular tank were used. In their study, sedimentation and dynamics of particle-laden flow were not considered. Good agreement was found considering different conditions, in particular ST velocity profiles and turbulent kinetic energy. Rostami et al. (2011) compared the rigid-lid assumption and VOF approach at the surface boundary. They showed that the results of VOF are more precise in comparison with fixed surface flow in STs. The rigid-lid assumption were over-estimated flow rates in the upper zone of the tank, while the VOF results were in closer agreement with observations. This difference is related to the dissipation of energy by the free surface method such that the predicted values are less than results of the confined surface.

The aim of this work is to extend the study of Razmi et al. (2009) to examine the hydrodynamics of several baffle configurations and evaluate the tank performance at the laboratory scale, and to consider the results in the light of existing understanding of coupled ST sediment and hydrodynamic interactions. Below, well-characterized laboratory experiments coupled with detailed numerical modeling are used to evaluate ST efficiency. Specifically, the effects of different values of $F r_{\text {in }}$ (inlet Froude number) and baffle configurations on the physical behavior are determined experimentally. Then, as FLUENT (FLUENT software, 2003) cannot simulate both the free surface and combined sediment-water flow, a 2D numerical model (hydrodynamic model combined with VOF and the advection-diffusion equation) is used to simulate ST hydrodynamics and sedimentation. The laboratory data are used to validate the numerical results. Then, the numerical model is used to simulate and assess the hydraulic efficiency of the baffled tank for different baffle positions and heights. The location and height of the baffle in an actual tank may also depend on removal scheme of accumulated particles or 
sludge in the bottom of the tank. However, the present study, both in the experiment and modeling, does not consider sludge removal because the inlet particle concentration is low, particles are not cohesive and the tank is for drinking water treatment. Therefore, the effluent flow is nearly as large as the influent flow.

\section{Experiments}

\subsection{Theoretical Background}

ST flow patterns for density-stratified fluids are different from those of a fluid with uniform density under the same external conditions and boundary geometry (Zhou and McCorquodale, 1992). The relative importance of inertial and gravity forces in a ST is related to the momentum and buoyancy flux at the inlet, and can be characterized in terms of the inlet Reynolds and Froude numbers, respectively $R e_{\text {in }}=\rho U_{0} h_{0} / \mu$, and $F r_{\text {in }}=U_{0}\left[g h_{0}\left(\rho / \rho_{r}-1\right)\right]^{-1 / 2}$ (Zhou and McCorquodale, 1992), where $g$ is the magnitude of gravitational acceleration, $h_{0}$ is the inlet height, $U_{0}$ is the inlet velocity, $\rho$ and $\mu$ are the fluid density and molecular viscosity, respectively, and $\rho_{r}$ is the reference density (clear water, 1000

$\left.\mathrm{kg} / \mathrm{m}^{3}\right) . F r_{\text {in }}$ reflects the effect of buoyancy forces in the inlet boundary condition (Tamayol et al., 2003). Here, the effect of the buoyancy force is quantified using two $F r_{\text {in }}$ values (Table 2).

\subsection{Experimental Setup and Procedure}

We used the same model setup as in Razmi et al. (2009). A laboratory apparatus (Fig. 1) at Sharif University of Technology, Iran, was used to study the (approximately) 2D flow resulting from the release of particle-laden water into the channel. The experiments were conducted in an 8-m long, 0.34$\mathrm{m}$ deep and 0.2-m wide rectangular channel with a flat bottom. Particle-laden fluid was prepared in a cylindrical stainless steel supply tank. The inlet current flow rate, $Q$, was measured using a DFM model 
ultrasonic Doppler flow meter, manufactured by Greyline ${ }^{1}$, with an accuracy of $10^{-5} \mathrm{~m}^{3} / \mathrm{min}$. The sediment concentration with a specific gravity of $2650 \mathrm{~kg} / \mathrm{m}^{3}$ and average grain size $\left(D_{50}\right)$ of $2 \times 10^{-5} \mathrm{~m}$ was used. The solid and freshwater was mixed to $\rho=1200 \mathrm{~kg} / \mathrm{m}^{3}$ in the supply tank, transferred to a constant-head weir by a circulation pump, then fed into the ST. Due to the low inlet concentrations in these experiments, the mixture viscosity is considered to be the same as that of freshwater (Zhou and McCorquodale, 1992).

Similar to previous studies on prototypes of rectangular tanks (Lyn and Rodi, 1992; Asgharzadeh et al., 2011), the inlet Reynolds number of $R e_{\text {in }}=4515$ was used. For all experiments, $Q$ was measured as about $4.2 \times 10^{-2} \mathrm{~m}^{3} / \mathrm{min}$, and fully developed turbulent flow conditions were assured at the tank entrance. Definitions of $s$ and $L$ (Table 2) are shown in Fig. 1. The height of the baffle within the tank, $b$, was $0.08 \mathrm{~m}$ and $h_{0}=1$ and $11 \mathrm{~cm}$ in the experiments. For each location, $3-6$ replicates were taken. All the measurements are presented in Figs. 2 and 3. A summary of the experimental conditions is provided in Table 2.

\subsection{Instrumentation and Data Collection}

A Nortek Acoustic Doppler Velocimeter ${ }^{2}$ (ADV), placed on a rail track next to the flume, was used to measure velocity. An advantage of the ADV is its ability to measure the flow in a small sampling volume located $5 \mathrm{~cm}$ away from the sensing elements, so inserting a probe into the flow did not unduly disturb the measurement. Data were collected for about $30-40 \mathrm{~s}$ at each point at the maximum available sampling rate of $25 \mathrm{~Hz}$. For this sampling rate, random noise in the signal reaches approximately $1 \%$ of the velocity range. Measurements within $5 \sim 7 \mathrm{~cm}$ of the surface boundary were unreliable due to acoustic effects in the surface layer and were discarded (Nortek ADV Specification

\footnotetext{
${ }^{1}$ http://www.greyline.com, last accessed: 16 October 2012

${ }^{2}$ http://www.nortek.com, last accessed: 16 October 2012
} 
User and Operation Manual, 1999). The experiments provided instantaneous velocities and timeaveraged velocity profiles. Mean velocities were calculated from temporal averaging of the recorded time series. Measurements at sections $(x=3.5 \mathrm{~m}, 4.5 \mathrm{~m}$; and $x=5.5 \mathrm{~m}, 6.5 \mathrm{~m})$ were performed simultaneously along the tank centerline. We did not measure the velocity close to the sides of the experimental tank. ST flow patterns are sensitive to the difference between the temperature of the entering and resident ST water (Taebi-Harandy and Schroeder, 2000). Water was used from a reservoir instead of the direct supply network to limit such differences. The mixture temperature was measured during the tests to confirm that the temperature variations did not occur. Density currents in the present work are due to particles and not temperature, since the experiments were carried out under (near-) isothermal conditions.

\section{Numerical Model}

Following Tamayol et al. (2010), the governing equations used to describe flow in the ST were the 2D Reynolds-Averaged Navier-Stokes equations, VOF (Volume-of-Fluid) for the free surface calculation, two-equation $k$ - $\varepsilon$ turbulence closure model and the advection-diffusion equation. The calculations were performed assuming a temperature of $20^{\circ} \mathrm{C}$. The initial flow field was specified as hydrostatic pressure and zero velocity. At the air-water interface, vertical fluxes of the turbulent kinetic energy $(k)$ and the turbulence dissipation rate $(\varepsilon)$ were set to zero. The settling velocity was modeled by a double exponential equation (Tamayol et al., 2010). At the inlet, both $U_{0}$ and sediment concentration were constant and known. The velocity log-law at the bed boundary layer for $k$ and $\varepsilon$ was used. No-slip conditions and zero concentration gradients were imposed on all solid boundaries. A zero-flux condition was applied as the top (free-surface) boundary condition for the sediment concentration. The governing equations were discretized using standard finite-difference methods with Cartesian coordinates, while a staggered grid was used for the calculation domain. The time step was determined 
by iteration until computational stability was achieved (Bakhtyar et al., 2008, 2009). Stability was controlled mainly by the local Courant number. Solution convergence was controlled dynamically by checking residuals. At the end of each solver iteration, the residual sum for each of the conserved variables was computed. These residuals go to zero as the solution converges (Bakhtyar et al., 2010). All presented results were checked for grid convergence, i.e., they are not noticeably changed by reducing the grid size. Results for a grid size of $8 \mathrm{~mm}$ are presented. The settling velocity was modeled following Zhou and McCorquodale (1992) and Tamayol et al. (2010). Since the constants in this model were determined by experiments, it can be said that the re-suspension of particles is considered indirectly by the model.

\section{Results}

The hydrodynamics of the turbulent particle-laden flow field with several baffle configurations were investigated experimentally and numerically. Not all possible ST variations (e.g., the tank dimensions and application of activated sludge) were modeled, as the focus was on the experimental configuration. However, the physical behavior that affects STs, including the flow hydrodynamics, details of sedimentation and hydraulic removal performance were investigated. First, the fluid equations were solved in the absence of sediments to find the quasi-steady flow field, which was reached when the velocity distributions within the tank showed little variation. Then, the sediments are released from the entrance and are simulated along the tank. The convergence was achieved when sediment concentrations in the outflow were stable (SL, Table 2). In brief, the following cases were investigated:

(i) baffled tanks (with two baffle configurations, cases 2 and 3 in Table 2), and (ii) tanks without a baffle (cases 1 and 4 in Table 2). 


\subsection{Experimental Observations and Numerical Validation}

The interaction of buoyancy and inlet momentum play a leading role in ST flow dynamics. The inflow density and velocity control the maximum velocity within the ST. Figure 2 illustrates the vertical distribution of horizontal velocities for particle-laden flow without and with baffles (cases 1-3, see Table 2). Measurements at a given location were replicated 3-6 times, collected over one or two days of experimentation.

The experimental data did not include sediment concentrations, i.e., we used velocity fields only for validation. However, these velocity fields are noticeably affected by the sediment load. The model was validated using ST hydrodynamic experimental data collected for both pure water and mixture conditions (Fig. 2). Good agreement was found considering different conditions, thus, the model is, at least, partially validated. The model has not been validated in the recirculation region since data were not collected there. On the other hand, the model computes recirculation, which affects flow in other parts of the tank. In particular, recirculation regions are created downstream of the inlet and mid baffles. The numerical model predicts well the velocity field in cases of no baffle as well as baffled flow. Without modelling the recirculation in the tank the model would be unable to predict the velocity field in the tank downstream and, consequently, model validation would fail.

In Fig. 2, the experimental data are compared with numerical results at different positions $(x / L=$ $0.44,0.56,0.69,0.82$, where $x / L$ is scaled horizontal length, panels, left to right, respectively). The results in these figures show that the simulated changes in the velocity profiles are in good agreement with the measurements in all cases. Both visual observations during the experiments and the numerical results confirm that the water height, denoted $h_{\text {ave }}$, in the experimental tank varied little between the different cases. Thus, within the tank the average velocity across any vertical profile is $U_{\text {ave }}=U_{0} h_{0} / H$. The results in Fig. 2 validate the numerical model and boundary conditions, momentum equations, as 
well as the turbulence closure model. The influence of sediment concentration is considered in the momentum equations because of the reduced gravity term.

Not surprisingly, the results demonstrate that the velocity profiles are influenced by the baffle position. Considering first case 1 (no baffle), Fig. 2a shows that the maximum velocity does not change with position along the tank up to $x / L=0.69$. At $x / L=0.82$, the maximum velocity decreases slightly, and its height in the tank increases, reflecting the influence of the exit location. However, for case $2(s / L$ $=0.15$ ), Fig. $2 \mathrm{~b}$ shows that maximum velocity increases with position along the tank (panels $1-2$ ), then in the final panel there is a momentum reduction compared with case 1 . The baffle at $s / L=0.15$ moves the jet upward and decreases the maximum velocity (compare the first panels in Fig. 2a,b). At $x / L=$ 0.56 , for case 1 the maximum velocity remains almost the same (Fig. 2a, panel 2), but it is near the midelevation of the tank in case 2 (Fig. $2 b$, panel 2). For case $3(s / L=0.5)$, the maximum velocity increases after the baffle, with reverse flow at the same location (Fig. 2c, panel 3: the velocity is negative for $y / H$ $>0.8$ ). Indeed, this baffle configuration yields the maximum velocity amongst all cases in Fig. 2. The baffle guides the suspended particles into the middle of the tank, increases considerably the maximum velocity, leads to formation of circulation zones and contributes to short-circuiting. In all cases in Fig. 2 , the last two vertical profiles $(x / L=0.69,0.82)$ show that the jet goes upward (due to the location of the exit weir) with a slight reduction in the maximum velocity. Generally, there was a lower maximum velocity and more uniformity in case 2 than in the other cases $\left(U / U_{\text {ave }}\right.$ is closer to unity, where $U$ is considered over the entire depth for a given $x$ ). The maximum velocities for case 3 are higher than case 1, and have less uniformity than the baffled flow in case 2 (panel 3 of Figs. 2a,c). To observe the impact of sediment concentration on the flow patterns, the velocity profiles for the no-sediment/no-baffle case are presented in the Fig. $2 \mathrm{~d}$. We observe that the velocity profiles are much more uniform without the sediment load, and that the presence of sediment leads to a greater flow velocity maximum at a given position along the tank. 
The experimental tank's entrance height, $h_{0}$, is a key parameter, along with the inlet velocity and particle concentration, controlling $F r_{\text {in }}$ (Krebs, 1991). The effects of $h_{0}$ on tank flow fields (no baffle) were compared for two different inlet heights $(1$ and $11 \mathrm{~cm})$. The velocity profiles for cases 1 and 4 are shown in Fig. 3.

High velocity and sediment concentration cause high momentum near the inlet. A part of this momentum remains in the flow along the tank and controls the maximum velocity in the subsequent flow. The higher inlet velocity in case 4 induces larger inertial forces (and higher velocity in the tank) in comparison to those found in case 1 . The reverse flow in case 4 , in comparison to that in case 1 , was due to the reduced slope (the angle between the tangent line to the curve at $y / H=0.8$ and the $x$-axis). As observed in Fig. 3 at $x / L=0.56$, the velocity near the bottom is larger than case 4 . Since $F r_{\text {in }}$ for case 1 is lower than unity, this increase of velocity may be attributed to the density current influence, which is noticeable along the middle of the tank.

\subsection{Sediment Concentration and Hydraulic Removal Performance}

To measure the settling tank performance, the normalized, vertically integrated flux-averaged sediment concentration was calculated (cf. Kreft and Zuber, 1978; Parker and van Genuchten, 1984; Sposito and Barry, 1987; Parlange et al., 1992):

$$
\bar{C}_{z}\left(x, t_{\infty}\right)=\frac{\int C\left(x, z, t_{\infty}\right) U\left(x, z, t_{\infty}\right) d z}{\int U\left(x, z, t_{\infty}\right) d z},
$$

where $C$ is the particle concentration, $t$ is the time, $t_{\infty}$ indicates that simulations have reached quasisteady state, $U$ is the horizontal velocity, $x$ and $z$ are the horizontal and vertical directions respectively, and $\bar{C}_{z}$ is the normalized sediment concentration. Recall that the simulations were run to quasi-steady state so the normalized sediment concentration is quasi-independent of $t$. At the tank entrance, all the 
sediment is suspended within the flow, so the difference $\bar{C}_{z}\left(0, t_{\infty}\right)-\bar{C}_{z}\left(L, t_{\infty}\right)$ is proportional to the mass of sediment that settles in the tank. Note that, since the influent was well-mixed, $\bar{C}_{z}\left(0, t_{\infty}\right)$ is equal to the influent concentration. The performance, $E$, of the settling tank is defined as (e.g., Tamayol et al., 2010):

$$
E=\frac{\bar{C}_{z}\left(0, t_{\infty}\right)-\mathrm{SL}}{\bar{C}_{z}\left(0, t_{\infty}\right)},
$$

where SL $=\bar{C}_{z}\left(L, t_{\infty}\right)=360,120,324$ and 416 , for cases $1-4$ are respectively For the baffled tank experiments, $E$ was 0.90 (best case) and 0.73 for cases 2 and 3, respectively. For the no baffle cases, we found, for case $1, E=0.70$, and for case $4, E=0.65$.

Figure 4 displays the normalized sediment concentration along the tank for different cases: no baffle (case 1 ), $s / L=0.15$ (case 2 ), $s / L=0.5$ (case 3 ). Typically, the amount of suspended sediment diminishes from the inlet point onwards. Where there is a baffle, the concentration peaks after its location. The greatest differences between the no-baffle and baffled cases are found at the baffle positions (e.g., at $x / L=0.15$ for case 2 and $x / L=0.5$ for case 3 ), where most sediment settling and deposition occurs.

For the no-baffle case, the simulation shows that the sediment concentrations reduce continually from the inlet $(1200 \mathrm{mg} / \mathrm{l})$ and drop to less than $400 \mathrm{mg} / \mathrm{l}$ at the tank's end $(x / L=1)$. It can be seen from Fig. 4 for case 3 (baffle at $s / L=0.5$ ) that the sediment concentration reduces from the inlet $(1200 \mathrm{mg} / \mathrm{l})$ to less than $300 \mathrm{mg} / \mathrm{l}$ at $x / L \approx 0.5$. This figure (for case 3 ) shows two minima located at $x / L \approx 0.5$ and 1 . The same sediment concentration is observed at the outlet for the cases of no baffle and with a baffle at $s / L=0.5$. Clearly, the baffle at $s / L=0.5$ hardly improves the sediment removal efficiency compared with the no-baffle case. Since the exit is at the top of the downstream end of the tank, the flow is 
generally upwards from the inlet to the exit. Thus, the baffle at $s / L=0.5$ does not greatly affect the deposition as compared with the no-baffle case. However, the sediment concentration clearly decreases along the tank for the baffle placed at $s / L=0.15$, since here the baffle impinges markedly on the flow pattern.

The $s / L \approx 0.15$ set up gives the most efficient results for present experimental conditions. To investigate the concentration distribution, the sediment concentration field for this case is presented. The increases in the normalized sediment concentrations near the baffles result from induced changes in flow patterns. To investigate the flow behavior, horizontal velocities at different positions near the baffle (before, at and after), for particle-laden flow with the baffle (case $2, s / L=0.15$ ) are shown in Fig. 5a. In baffled tanks, the baffles generated reverse flow (contour does not reach the bottom because of the baffle). This reduces the normalized sediment concentration, which is not the case for the ST without a baffle. The vertical velocities at different positions near the baffle are shown in Fig. 5b. Before the baffle location, the vertical velocity is high, and the flow has a tendency towards the free surface, which also moves sediments towards the surface. But, in the rest of ST, vertical velocities decrease and become insignificant.

Figure 6 a gives the simulated contours of sediment concentration for particle-laden flow with the baffle (case $2, s / L=0.15$ ), while Fig. $6 b$ illustrates the vertical distribution of the sediment concentration profile (case 2) at different positions. Concentrations decreased with distance from the bed in all parts of tank. Furthermore, the baffle stops the high particle concentration at the inlet area from directly entering the rest of the tank. The sediment concentration near the entrance (up to 1145 $\mathrm{mg} / \mathrm{l}$ ) is an order of magnitude greater than that near the outlet (up to $120 \mathrm{mg} / \mathrm{l}$ ). On the other hand, collection of all the sediment near one part of the tank would reduce the tank maintenance interval. To examine further the behavior and effect of the sediment particles on the physical behavior of ST, the 
streamlines were calculated (Fig. 6c.) From Fig. 6c, it can be seen that two circulation zones occur near the entrance and after the baffle (the first one between $x / L=0$ to $0.17 \mathrm{~m}$, and second one between $x / L=$ 0.17 to $0.42 \mathrm{~m}$ ). In spite of these regions, the circulation volume is minimized and it seems that the baffle divides the dead zone into two parts.

Since particle settling is affected by both density and flow rate, it is necessary to combine both these factors to have an indication of where settlement occurs, for which the following empirical function was constructed:

$$
S=\left(1-\frac{|U|}{U_{0}}\right) \frac{C}{C_{0}},
$$

where $C_{0}$ and $U_{0}$ are the solid concentration and velocity of the inlet, respectively. $C$ and $U$ are the modeled solid concentration and velocity of the inlet. This function was constructed such that $0 \leq S \leq 1$. Sedimentation is more likely with increasing $S$. Figure 7 shows the simulated contours of $S$ in the settling tank. $S$ has a maximum value along the bottom of the tank since sediment concentration is near its maximum and velocity is close to zero there. Additionally, according to Eq. (3), $S$ is equal to zero at the entrance because $U=U_{0}$ there. Figure 7 reveals that high sediment settling occurs before the baffle position. Since the velocity close to bed before the baffle is very low and the location is near the entrance, $C$ is very high and thus the magnitude of $\mathrm{S}$ is a maximum. However, sediment re-suspension is likely in this location due to the high flow rate just above the bottom of the tank, so the magnitude of $S$ decreases correspondingly. $S$ decreases along the tank, but increases towards the tank's end because of the velocity reduction there. Despite its obvious limitations, the contours of $S$ provide a rough estimate of the possible distribution of sediment along the tank bottom. However, experimental data on sediment concentrations in the tank would be necessary to confirm the utility of Eq. (3). 
To find the most efficient baffle position and height, the tank efficiency (in terms of SL and $E$ ) was explored for various baffle locations $(s / L)$ and various baffle heights $(b)$. Figure 8 a gives relationships between SL and baffle positions, while Fig. $8 \mathrm{~b}$ shows the effects of baffle positions on the tank performance. The SL increased with increasing $s / L$, and $E$ increased when the baffle position was nearer to the inlet (except for $s / L=0.05$ ). As the baffle location moves away from the inlet, the suspended sediment is directed upwards towards the outlet, reducing the sediment removal and tank efficiency. Baffles near the entrance (small $s / L$ ) suppress the velocity and enhance sediment deposition, thus reducing the chance for short-circuiting. If the baffle position is very close to inlet $(s / L=0.05)$, then suspended sediments do not have enough time to settle. The best position of the baffle (minimum SL and maximum $E$ ) was found to be at $s / L=0.10 \sim 0.20$. In addition, the results show that, eventually, baffles have no effect on tank performance ( $s / L>0.7$ for present setup).

Panels a and c of Fig. 9 show tank performance and SL versus baffle positions (i.e., $s / L=0.05$, $0.15,0.25,0.35)$ for different baffle heights $(b=4,8,10,12,14 \mathrm{~cm})$, while Fig. $9 \mathrm{~b}$ and d give tank performance and SL versus baffle heights at different locations. The results show that the shortest and highest baffle heights $(4$ and $12 \mathrm{~cm}$ ) reduce tank performance and increase SL. Baffle heights larger than the optimum enhance upward flow before the baffle and move suspended sediments to the surface. Since the flow velocity before the baffle is high, this condition lifts the solids from the bottom and increases the chance for short-circuiting, leading to reduced tank performance. Conversely, if the baffle height is insufficient (such cases approach the no-baffle condition), the baffle effect on the circulation volume and flow field in the tank is reduced, and tank performance is decreased. Tank performance and SL for different baffle configurations in the numerical experiments are shown in Table 3. The best performance of the tank occurs for the case with baffle height of $25 \sim 30 \%$ of water depth. In addition, by increasing the baffle height, the distance of the best baffle position from the inlet increased (for $b=$ $10 \mathrm{~cm}$, the best baffle position is $s / L=0.15$; while for $b=12 \mathrm{~cm}$, the baffle best position is $s / L=0.25$ ). 


\section{Concluding Remarks}

A series of experimental measurements as well as numerical modeling were carried out to investigate the effect of baffle positions on the performance of the baffled ST. The model was able to simulate free-surface tracking, sediment distribution and velocity profiles, and gave predictions that agreed well with laboratory data. The validated model was then employed to simulate and assess the hydraulic efficiency for the baffled tank configuration used in the laboratory experiments.

The simulation results demonstrated that the baffle configuration created significantly different flow fields in the tank and that proper baffle placement improved the ST performance. The location of baffle near the entrance dissipates the inlet jet energy more efficiently. It diminishes the maximum velocity magnitude along the tank and reduces sediment re-suspension after the baffle position. In contrast, with increasing distance of the baffle from the entrance, the velocity magnitude remains high and leads to particle re-suspension. For the configuration analyzed here (Fig. 1), the best baffle configuration was determined as $s / L=0.15$ along with an inlet baffle height of $h_{0} / H=0.32$. In this case, $90 \%$ of the particles stay in the ST. In addition, the same sediment concentration was observed at the outlet for the cases of no baffle and with a baffle at $s / L=0.5$, i.e., an inappropriately baffled tank does not improve the ST efficiency in comparison with a non-baffled one. In summary, the numerical experiments show that the best position of the baffle is relatively close to the entrance jet $(s / L=0.10 \sim$ 0.20 ), while the best baffle height is around $25 \sim 30 \%$ of the water depth.

\section{Acknowledgements}

Experimental facilities and logistical support were provided by Sharif University of Technology. Support of the Swiss National Foundation (SNF 200021-135322) is acknowledged. 


\section{References}

Adams, E.W., and Rodi, W. 1990. Modeling flow and mixing in sedimentation tanks. ASCE Journal of Hydraulic Engineering, 116(7): 895-911. doi:10.1061/(ASCE)0733-9429(1990)116:7(895).

Ahmed, E.H., Kamel, A., and Abdel-Jawad, S. 1996. Experimental determination of the optimal location and contraction of sedimentation tank baffles. Water, Air, and Soil Pollution, 92(3-4): 251-271. doi:10.1007/BF00283562.

American Water Works Association. 1990. Water treatment plant design. McGraw Hill, New York, USA.

Bakhtyar, R., Barry, D.A., Yeganeh-Bakhtiary, A., and Ghaheri, A. 2008. Numerical simulation of surf-swash zone motions and turbulent flow. Advances in Water Resources, 32(2): 250-263. doi:10.1016/j.advwatres.2008.11.004.

Bakhtyar, R., Ghaheri, A., Yeganeh-Bakhtiary, A., and Barry, D.A. 2009. Process-based model for nearshore hydrodynamics, sediment transport and morphological evolution in the surf and swash zones. Applied Ocean Research, 31(1): 44-56. doi:10.1016/j.apor.2009.05.002.

Bakhtyar, R., Razmi, A.M., Barry, D.A., Yeganeh-Bakhtiary, A., and Zou, Q.-P. 2010. Air-water two-phase flow model of turbulent surf and swash zone wave motions. Advances in Water Resources, 33(12): 1560-1574. doi:10.1016/j.advwatres.2010.09.007.

Brescher, U., Krebs, P., and Hager, W.H. 1992. Improvement of flow in final settling tanks. ASCE Journal of Environmental Engineering, 188(3): 307-321. doi:10.1061/(ASCE)0733-9372(1992)118:3(307).

Celik, I., Rodi, W., and Stamou, A.I. 1985. Prediction of hydrodynamic characteristics of rectangular settling tanks. International Symposium of Refined Flow Modeling and Turbulence Measurements, Iowa, USA, pp. 641-651.

Ekama, G.A., Barnard, J., and Gunthert, F. 1997. Secondary settling tanks: Theory, modeling, design and operation. IWA Scientific and Technical Rep. No. 6, International Water Association, London, UK.

FlowScience. 2003. Flow-3D user manual; excellence in flow modeling software, v 8.2, Santa Fe, New Mexico, USA.

FLUENT incorporated. 2003. FLUENT 6.1 user’s guide. Lebanon, New Hampshire, USA. 
Goula, A.M., Kostoglou, M., Karapantsios, T.D., and Zouboulis, A.I., 2008. A CFD methodology for the design of sedimentation tanks in potable water treatment case study: The influence of a feed flow control baffle. Chemical Engineering Journal, 140(1-3): 110-121. doi:10.1016/j.cej.2007.09.022.

Huggins, D.L., Piedrahita, R.H., and Rumsey, T. 2005. Use of computational fluid dynamics (CFD) for aquaculture raceway design to increase settling effectiveness. Aquaculture Engineering, 33(3): 167-180. doi:10.1016/j.aquaeng.2005.01.008.

Krebs, P. 1991. The hydraulics of final settling tanks. Water Science and Technology, 23(4-6), 1037-1046.

Krebs, P. 1995. Success and shortcomings of clarifier modeling. Water Science and Technology, 31(2): 181-191. doi:10.1016/0273-1223(95)00191-O.

Krebs, P., Stamou, A.I., García-Heras, J.L., and Rodi, W. 1996. Influence of inlet and outlet configuration on the flow in secondary clarifiers. Water Science and Technology, 34(5-6): 1-9. doi:10.1016/0273-1223(96)00622-1.

Krebs, P., Vischer, D., and Gujer, W. 1995. Inlet-structure design for final clarifiers. ASCE Journal of Environmental Engineering, 121(8): 558-566. doi:10.1061/(ASCE)0733-9372(1995)121:8(558).

Kreft, A., and Zuber, A. 1978. On the physical meaning of the dispersion equation and its solutions for different initial and boundary conditions. Chemical Engineering Science, 33(11): 1471-1480. doi:10.1016/0009-2509(78)85196-3.

Lawler, D.F., and Benjamin, M.M., 2011. Water treatment engineering: Physical and chemical processes. McGraw-Hill, Boston, Massachusetts, USA.

Liu, B., Ma, J., Luo, L., Bai, Y., Wang, S., and Zhang, J. 2010. Two dimensional LDV measurement, modeling, and optimal design of rectangular primary settling tanks. ASCE Journal of Environmental Engineering, 136(5): 501-507. doi:10.1061/(ASCE)EE.1943-7870.0000186.

Lyn, D.A. and Rodi, W. 1992. Turbulence measurements in model settling tank. ASCE Journal of Hydraulic Engineering, 116(1): 3-21.

Lyn, D.A., Stamou, A.I., and Rodi, W. 1992. Density currents and shear-induced flocculation in sedimentation tanks. ASCE Journal of Hydraulic Engineering, 118(6): 849-867. doi:10.1061/(ASCE)0733-9429(1992)118:6(849). 
Manual on water supply and treatment. Central Public Health and Environmental Engineering Organisation, Ministry of Urban Development, 1999 - Technology \& Engineering - 741 pp., India.

McCorquodale, J.A., Griborio, A., and Georgiou, I. 2006. Application of a CFD model to improve the performance of rectangular clarifiers. Water Environmental Federation WEFTEC.06, pp. 310-320.

McCorquodale, J.A. and Zhou, S., 1993. Effects of hydraulic and solids loading on clarifier performance. Journal of Hydraulic Research, 31(4): 461-477.

Parker, D.S., Kinnear, D.J., and Wahlberg, E.J. 2001. Review of folklore in design and operation of secondary clarifiers. ASCE Journal of Environmental Engineering, 127(6): 476-484. doi.org/10.1061/(ASCE)0733-9372(2001)127:6(476).

Parker, J.C., and van Genuchten, M.Th. 1984. Flux-averaged and volume-averaged concentrations in continuum approaches to solute transport. Water Resources Research, 20(7): 866-872. doi:10.1029/WR020i007p00866.

Parlange, J.-Y., Starr, J.L., van Genuchten, M.Th., Barry, D.A., and Parker, J.C. 1992. Exit condition for miscible displacement experiments in finite columns. Soil Science, 153(3): 165-171. doi:10.1097/00010694-199203000-00001.

Razmi, A., Firoozabadi, B., and Ahmadi, G. 2009. Experimental and numerical approach to enlargement of performance of primary settling tanks. Journal of Applied Fluid Mechanics, 2(1): 1-12.

Rostami, F., Shahrokhi, M., Md Said, M.A., Abdullah, R., and Syafalni, S. 2011. Numerical modeling on inlet aperture effects on flow pattern in primary settling tanks. Applied Mathematical Modelling, 35(6): 3012-3020. doi:10.1016/j.apm.2010.12.007.

Shahrokhi, M., Rostami, F., Md Said, M.A., Sabbagh-Yazdi, S., and Syafalni, S. 2011. The effect of number of baffles on the improvement efficiency of primary sedimentation tanks. Applied Mathematical Modelling, 36(8): 3725-3735. doi.org/10.1016/j.apm.2011.11.001.

Shahrokhi, M., Rostami, F., Md Said, M.A., Sabbagh-Yazdi, S., Syafalni, S., and Abdullah, R. 2012. The effect of baffle angle on primary sedimentation tank efficiency. Canadian Journal of Civil Engineering, 39(3): 293-303. doi:10.1139/L2012-002.

Smethurst, G. 1992. Basic water treatment for application worldwide. Second Edition, Thomas Telford, London, UK. 
Sposito, G., and Barry, D.A. 1987. On the Dagan model of solute transport in groundwater: Foundational aspects. Water Resources Research, 23(10): 1867-1875. doi:10.1029/WR023i010p01867.

Stamou, A., Theodoridis, G., and Xanthopoulos, K. 2009. Design of secondary settling tanks using a CFD model. ASCE Journal of Environmental Engineering, 135(7): 551-561. doi:10.1061/(ASCE)0733-9372(2009)135:7(551).

Taebi-Harandy, A., and Schroeder, E.D. 2000. Formation of density currents in secondary clarifier. Water Research, 34(4): 1225-1232. doi:10.1016/S0043-1354(99)00261-4.

Tamayol, A., Firoozabadi, B., and Ahmadi, G. 2008. Determination of settling tanks performance using an EulerianLagrangian method. Journal of Applied Fluid Mechanics, 1(1): 43-54.

Tamayol, A., Firoozabadi, B., and Ashjari, M.A. 2010. Hydrodynamics of secondary settling tanks and increasing their performance using baffles. ASCE Journal of Environmental Engineering, 136(1): 32-39. doi:10.1061/(ASCE)EE.19437870.0000126.

Technical guidelines for the construction and management of drinking water treatment plant. A Manual for Field Staff and Practitioners. Developed in partnership with UNICEF, 2009. (http://www.bsf-south-sudan.org, last accessed: 16 October 2012).

Wang, X., Zhou, S., Li, T., Zhang, Z., Sun, Y., and Cao, Y. 2011. Three-dimensional simulation of the water flow field and the suspended-solids concentration in a circular sedimentation tank. Canadian Journal of Civil Engineering, 38(7): 825836. doi:10.1139/L11-049.

Xanthos, S., Gong, M., Ramalingam, K., Fillos, J., Deur, A., Beckmann, K., and McCorquodale, J. A. 2010. Performance assessment of secondary settling tanks using CFD modeling. Water Research Management, 25(4): 1169-1182. doi: $10.1007 / \mathrm{s} 11269-010-9620-1$.

Yoon, T.H., and Lee, O.S. 2000. Hydraulic behavior and removal efficiency of settling tanks. KSCE Journal of Civil Engineering, 4(1): 53-57. doi:10.1007/BF02829174.

Zhou, S.P., and McCorquodale, J.A. 1992. Modeling of rectangular settling tanks. ASCE Journal of Hydraulic Engineering, 118(10): 1391-1405. doi.org/10.1061/(ASCE)0733-9429(1992)118:10(1391). 
Table 1. Previous studies on baffled rectangular STs.

\begin{tabular}{|c|c|c|c|}
\hline Author(s) & Approach & Baffle types & Remarks \\
\hline $\begin{array}{l}\text { Zhou and } \\
\text { McCorquodale } \\
\text { (1992) }\end{array}$ & $\begin{array}{l}\text { Numerical model. 2D } \\
\text { steady flow, } k-\varepsilon \\
\text { turbulence closure }\end{array}$ & Inlet baffle & A baffle can reduce entrainment into the influent plume \\
\hline Krebs (1995) & $\begin{array}{l}\text { 2D finite volume, } k-\varepsilon \\
\text { turbulence closure }\end{array}$ & $\begin{array}{l}\text { Inlet and outlet } \\
\text { baffles }\end{array}$ & $\begin{array}{l}\text { Baffle configuration markedly affected streamline } \\
\text { patterns }\end{array}$ \\
\hline $\begin{array}{l}\text { Taebi-Harandy et } \\
\text { al. (2000) }\end{array}$ & Experiments & $\begin{array}{l}\text { Inlet, } \\
\text { intermediate } \\
\text { and outlet } \\
\text { baffles }\end{array}$ & $\begin{array}{l}\text { A temperature difference resulted in formation of } \\
\text { density currents. Presence of inlet or intermediate } \\
\text { baffles had little impact on the formation of density } \\
\text { currents }\end{array}$ \\
\hline $\begin{array}{l}\text { Huggins et al. } \\
\text { (2005) }\end{array}$ & $\begin{array}{l}\text { 3D Navier-Stokes } \\
\text { equations, } k-\varepsilon \\
\text { turbulence closure }\end{array}$ & $\begin{array}{l}\text { Intermediate } \\
\text { baffle }\end{array}$ & $\begin{array}{l}\text { Removal efficiency strongly dependent on the size of } \\
\text { the input suspended solids. The baffle can improve } \\
\text { settling conditions for a certain range of particle sizes }\end{array}$ \\
\hline $\begin{array}{l}\text { Goula et al. } \\
(2008)\end{array}$ & $\begin{array}{l}\text { 2D finite volume, } k-\varepsilon \\
\text { turbulence closure }\end{array}$ & $\begin{array}{l}\text { Intermediate } \\
\text { baffle }\end{array}$ & $\begin{array}{l}\text { An extended baffle can provide better influent mixing } \\
\text { and sedimentation performance compared with a short } \\
\text { baffle }\end{array}$ \\
\hline $\begin{array}{l}\text { Tamayol et al. } \\
\text { (2008) }\end{array}$ & $\begin{array}{l}\text { 2D finite volume, } k-\varepsilon \\
\text { turbulence closure }\end{array}$ & $\begin{array}{l}\text { Inlet and } \\
\text { intermediate } \\
\text { baffles }\end{array}$ & $\begin{array}{l}\text { Baffles can improve settling conditions. Free surface } \\
\text { tracking not considered }\end{array}$ \\
\hline $\begin{array}{l}\text { Stamou et al. } \\
(2009)\end{array}$ & $\begin{array}{l}\text { 2D finite volume, } k-\varepsilon \\
\text { turbulence closure }\end{array}$ & $\begin{array}{l}\text { Inlet and } \\
\text { intermediate } \\
\text { baffles }\end{array}$ & $\begin{array}{l}\text { Model was for a specific set of conditions for a specific } \\
\text { ST }\end{array}$ \\
\hline $\begin{array}{l}\text { Xanthos et al. } \\
\text { (2010) }\end{array}$ & $\begin{array}{l}\text { 3D CFD program, } k-\varepsilon \\
\text { turbulence closure }\end{array}$ & $\begin{array}{l}\text { Different inlet and in- } \\
\text { tank baffle } \\
\text { configurations }\end{array}$ & The in-tank baffle reduced recirculation \\
\hline $\begin{array}{l}\text { Tamayol et al. } \\
\text { (2010) }\end{array}$ & $\begin{array}{l}\text { 2D Navier-Stokes } \\
\text { equation, } k-\varepsilon \text { turbulence } \\
\text { closure }\end{array}$ & $\begin{array}{l}\text { Inlet and intermediate } \\
\text { baffles }\end{array}$ & $\begin{array}{l}\text { For high values of } R e_{\text {in }} \text {, the flow field was not affected } \\
\text { by } F r_{\text {in }} \text {. Model not validated with experimental data }\end{array}$ \\
\hline $\begin{array}{l}\text { Rostami et al. } \\
\text { (2011) }\end{array}$ & $\begin{array}{l}2 \mathrm{D} \text { finite difference, } k-\varepsilon \\
\text { turbulence closure }\end{array}$ & Inlet baffles & $\begin{array}{l}\text { Different entrance heights were examined. It was also } \\
\text { shown that VOF method results are more accurate than } \\
\text { using the rigid-lid assumption in the surface boundary } \\
\text { condition }\end{array}$ \\
\hline $\begin{array}{l}\text { Shahrokhi et al. } \\
\text { (2012) }\end{array}$ & $\begin{array}{l}\text { 2D finite difference, } k-\varepsilon \\
\text { turbulence closure }\end{array}$ & Intermediate baffles & A $90^{\circ}$ baffle angle produced the best performance \\
\hline
\end{tabular}


Table 2. Experiments performed using the tank shown in Fig. 1 . The column $s / L$ gives the baffle location, if present.

\begin{tabular}{|c|c|c|c|c|c|}
\hline Case & $\begin{array}{c}\mathrm{SL}(\mathrm{mg} / \mathrm{l} \text {, as calculated by the } \\
\text { numerical model) }\end{array}$ & Inlet height, $h_{0}(\mathrm{~cm})$ & $F r_{\text {in }}$ & $s / L$ & Flow condition \\
\hline 1 & 360 & 11 & 0.88 & - & Particle-laden flow \\
\hline 2 & 120 & 11 & 0.88 & 0.15 & Particle-laden flow \\
\hline 3 & 324 & 11 & 0.88 & 0.5 & Particle-laden flow \\
\hline 4 & 416 & 1 & 32.26 & - & Particle-laden flow \\
\hline
\end{tabular}


Table 3. Tank performance $(E)$ and SL for different baffle configurations (baffle heights and positions) in the numerical experiments. Bold face indicates the best performance and corresponding baffle heights in each baffle location.

\begin{tabular}{|c|c|c|c|}
\hline$s / L$ & $b(\mathrm{~cm})$ & $E(\%)$ & $\mathrm{SL}(\mathrm{mg} / \mathrm{l})$ \\
\hline \multirow{5}{*}{0.05} & 4 & 0.81 & 228 \\
\hline & 8 & 0.85 & 180 \\
\hline & 10 & 0.84 & 192 \\
\hline & 12 & 0.83 & 204 \\
\hline & 14 & 0.79 & 252 \\
\hline \multirow{5}{*}{0.15} & 4 & 0.83 & 204 \\
\hline & 8 & 0.9 & 120 \\
\hline & 10 & 0.91 & 117 \\
\hline & 12 & 0.87 & 156 \\
\hline & 14 & 0.81 & 228 \\
\hline \multirow{5}{*}{0.25} & 4 & 0.8 & 240 \\
\hline & 8 & 0.86 & 168 \\
\hline & 10 & 0.87 & 156 \\
\hline & 12 & 0.89 & 132 \\
\hline & 14 & 0.84 & 192 \\
\hline \multirow{5}{*}{0.35} & 4 & 0.74 & 312 \\
\hline & 8 & 0.78 & 264 \\
\hline & 10 & 0.77 & 276 \\
\hline & 12 & 0.79 & 252 \\
\hline & 14 & 0.75 & 300 \\
\hline No baffle & - & 0.70 & 360 \\
\hline
\end{tabular}




\section{FIGURE CAPTIONS}

Fig. 1. (a) Diagram of the experimental setup. Symbols: $h_{0}$ is the inlet height; $H, b, s$ and $L$ are geometrical variables defining different cases. In all experiments, $H=0.34 \mathrm{~m}, b=0.08 \mathrm{~m}$ and $L=8$ m. (b) Photograph of the experimental tank.

Fig. 2. Vertical distribution of horizontal velocity in the experimental tank at $x / L=0.44,0.56,0.69$, 0.82 for (a) case 1 , no baffle; (b) case $2, s / L=0.15$; (c) case 3, $s / L=0.5$; (d) no baffle, no sediment (Razmi et al., 2009). Symbols are experimental data, dashed lines are numerical results and $y / H$ is scaled vertical length.

Fig. 3. Vertical distribution of horizontal velocity in the experimental tank at $x / L=0.56,0.69,0.82$ for the no-baffle cases: case $1\left(h_{0} / H=0.32\right)$ and case $4\left(h_{0} / H=0.03\right)$. Dashed lines represent case 1 and solid lines case 4 (lines are numerical results and symbols are experimental data). The horizontal axis shows the $U / U_{\text {ave }}$ at different positions in the tank and vertical axis is the scaled vertical length.

Fig. 4. Numerical results for normalized sediment concentration along the tank for different cases, no baffle (case 1$), s / L=0.15$ (case 2$)$, and $s / L=0.5$ (case 3$)$.

Fig. 5. (a) Horizontal velocity and (b) vertical velocity distributions at different positions near the baffle (before, at the baffle and after the baffle, listed in the figure) for particle-laden flow with a baffle case $(s / L=0.5$, case 2$)$.

Fig. 6. (a) Simulated contours of sediment concentration (units: mg/l), (b) vertical concentration distribution at different locations, $x / L$ (listed in the figure), and (c) simulated streamline for particleladen flow with a baffle (case 2).

Fig. 7. Simulated contours of $S$ for particle-laden flow with a baffle (case 2). 
Fig. 8. (a) Tank performance versus baffle position and (b) SL versus baffle position.

Fig. 9. (a) Tank performance versus baffle position for different heights (listed in the figure), (b) tank performance versus baffle height at different locations, $x / L$ (listed in the figure), (c) SL versus baffle position for different heights, and (d) SL versus baffle height at different locations. 


\section{FIGURES}

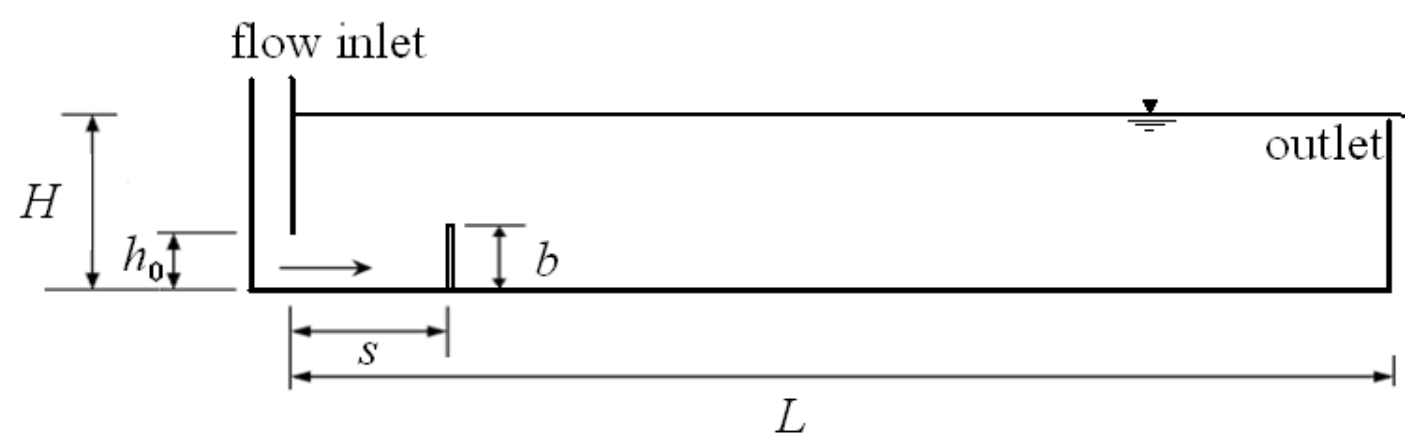

(a)

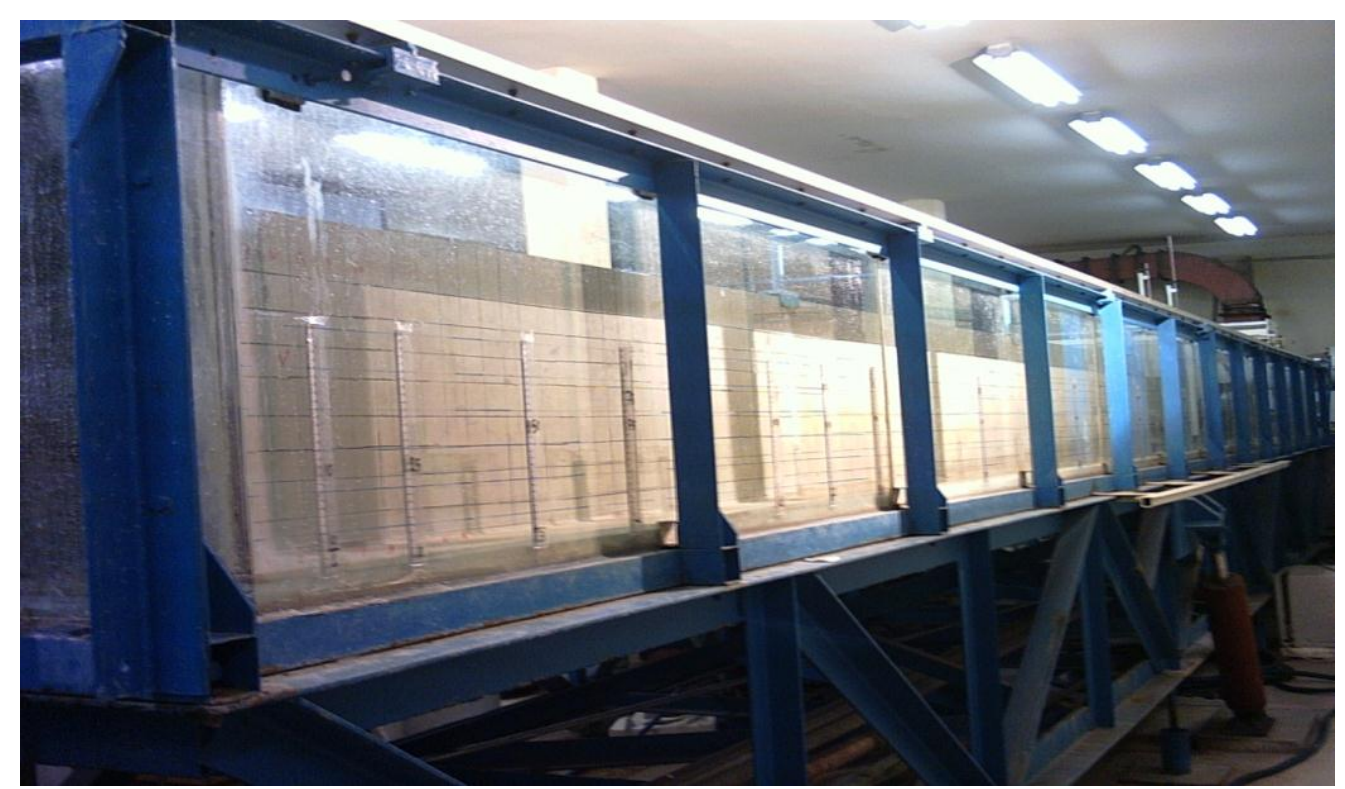

(b)

Fig. 1 

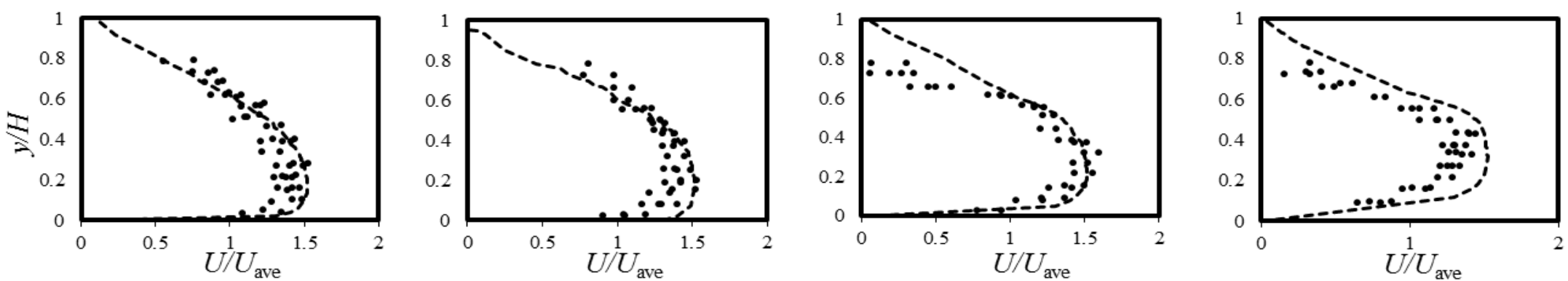

(a)
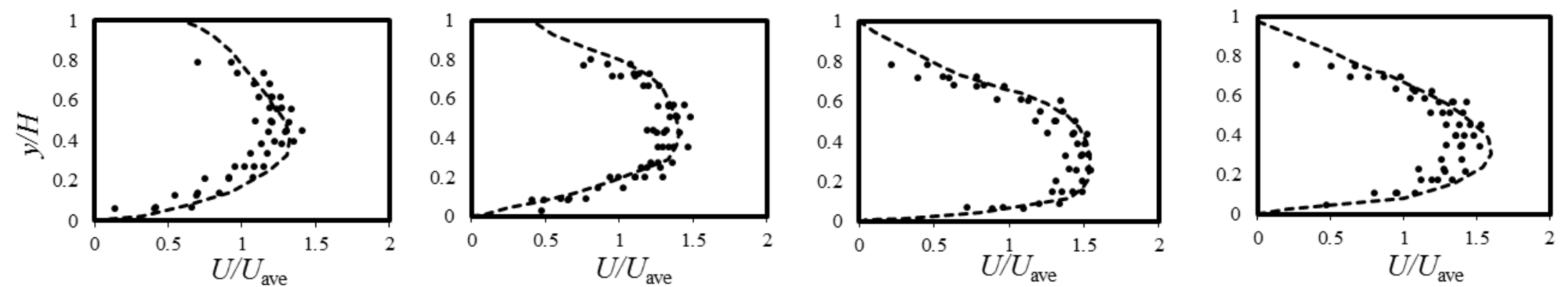

(b) 

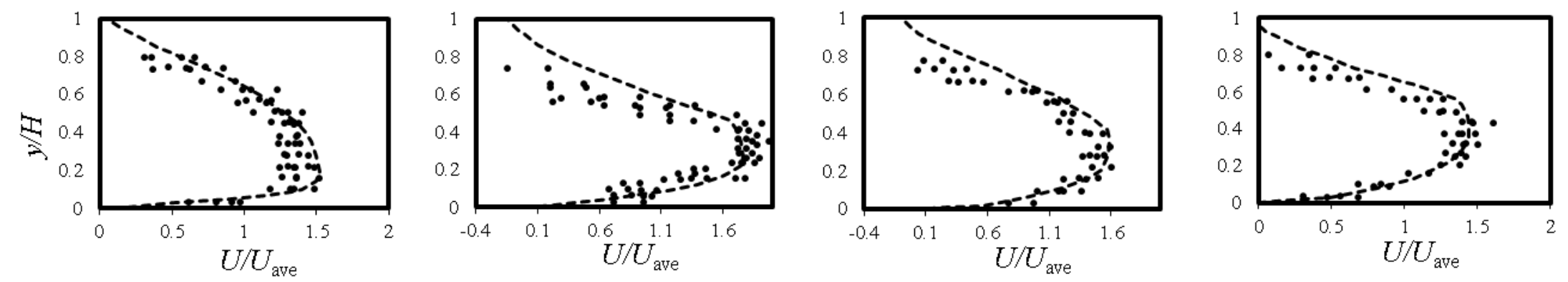

(c)
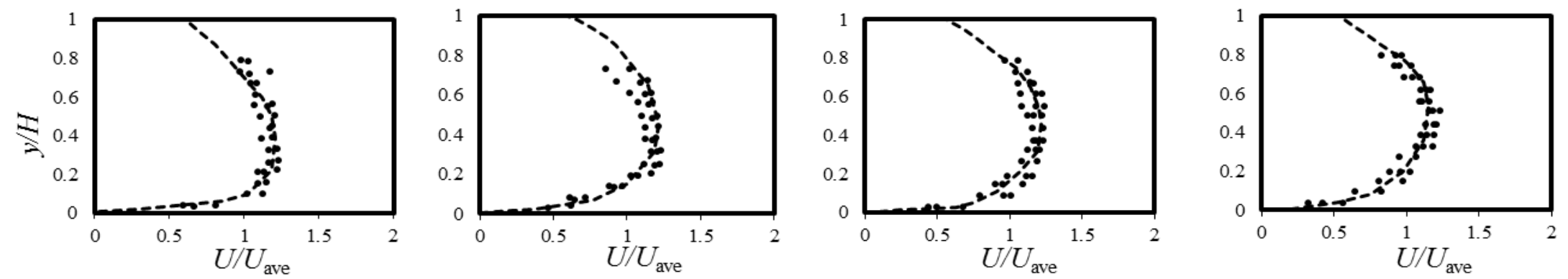

(d)

Fig. 2 

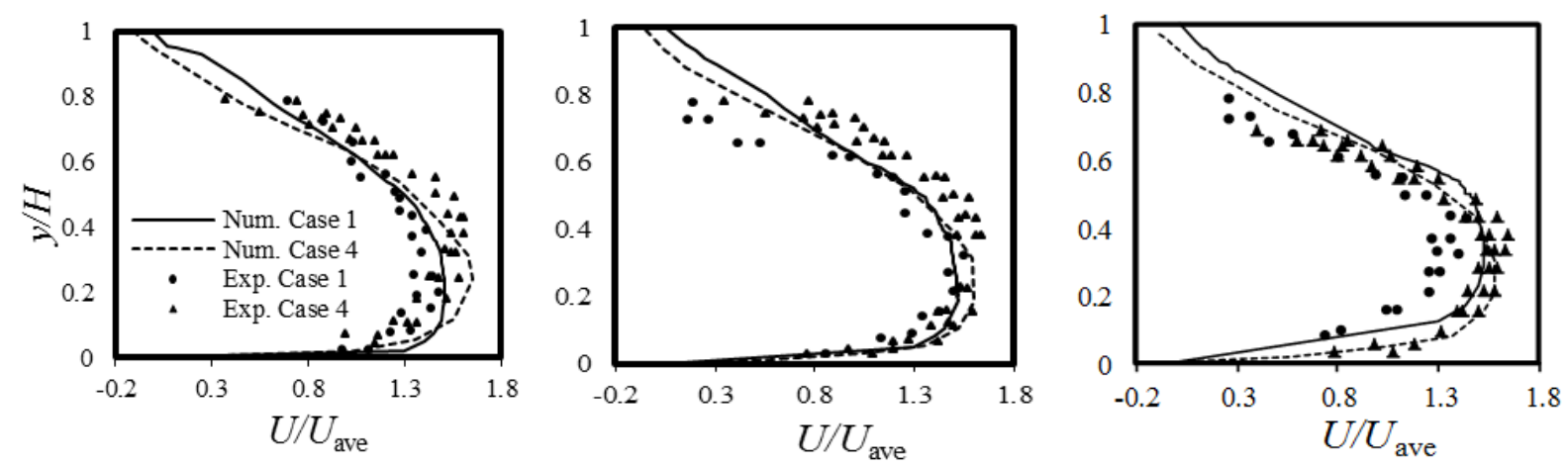

Fig. 3 


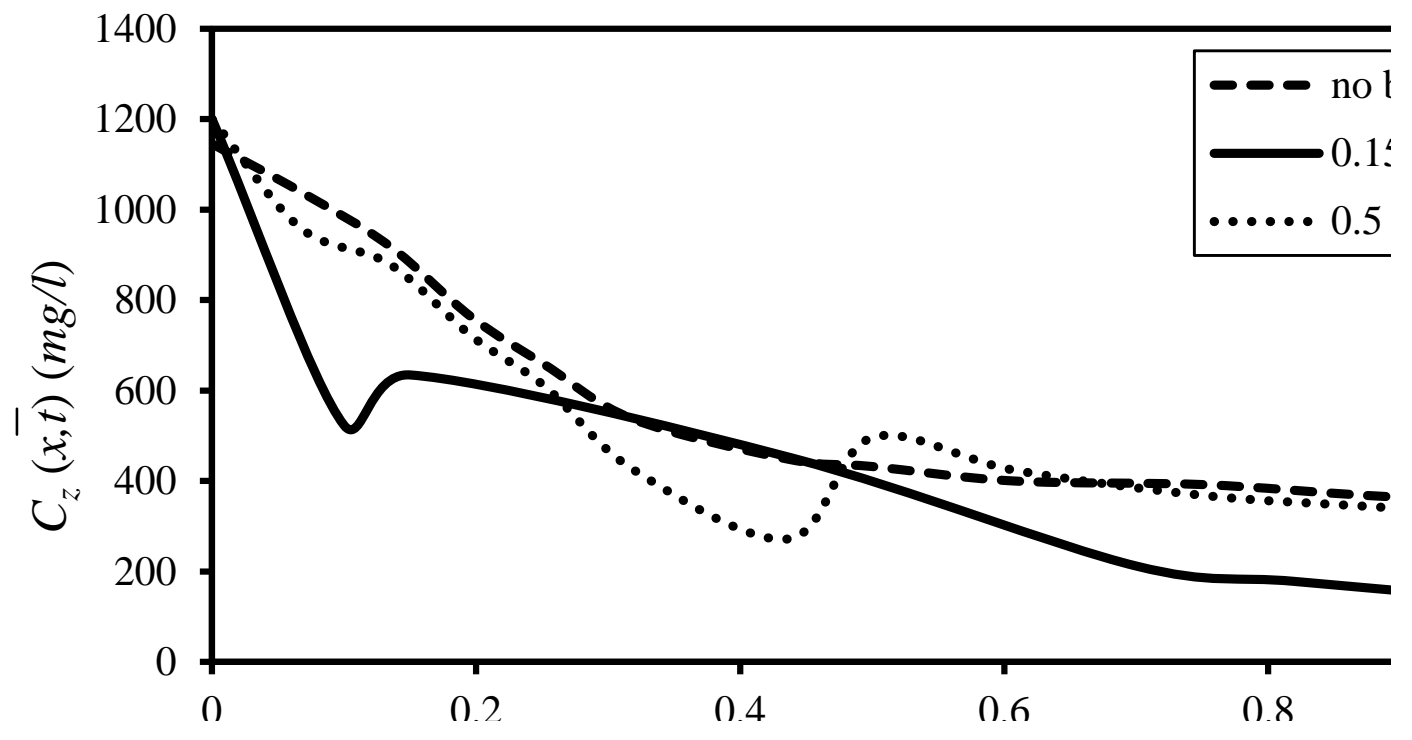

Fig. 4 


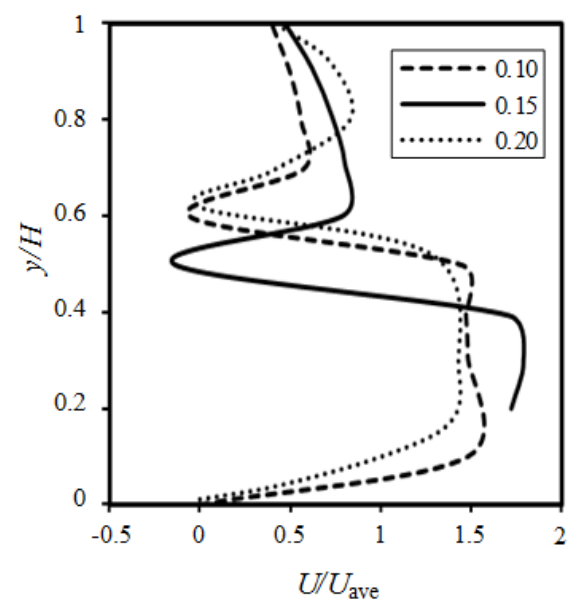

(a)

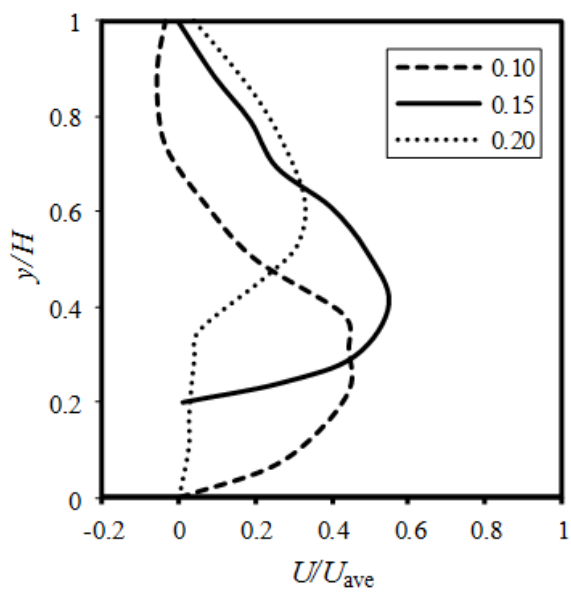

(b)

Fig. 5 


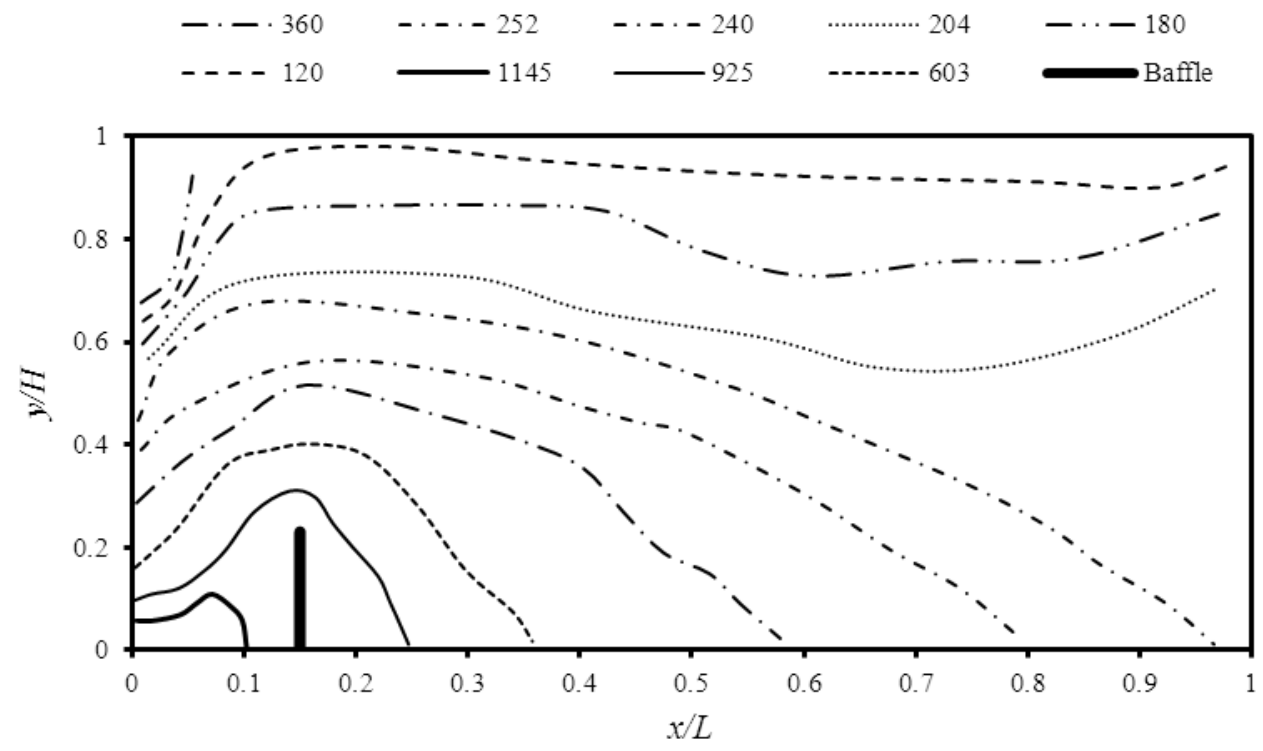

(a)

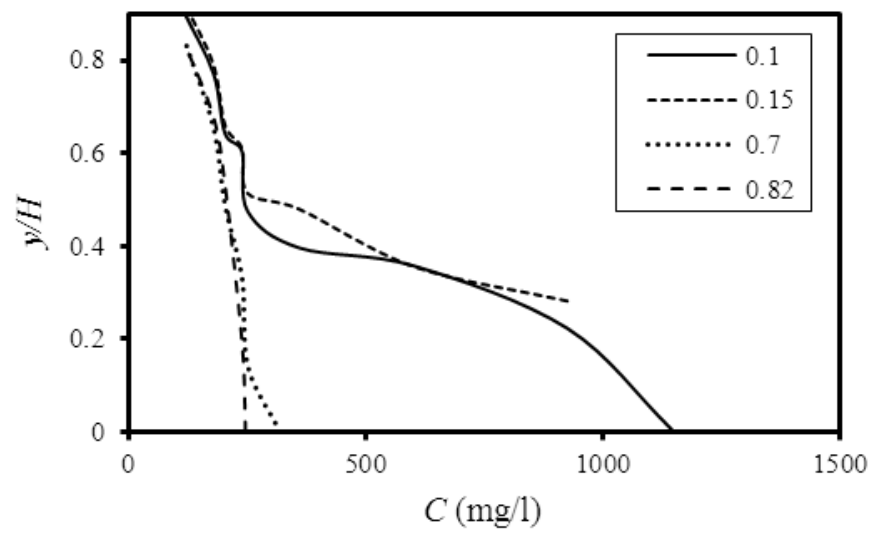

(b)

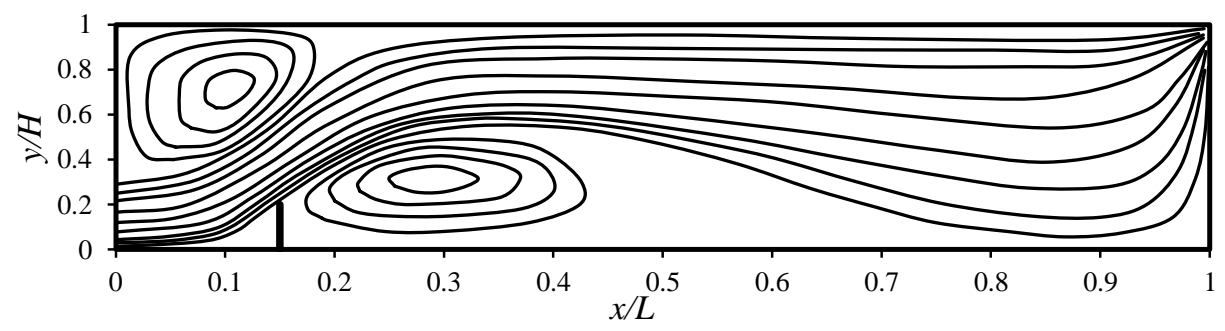

(c)

Fig. 6 


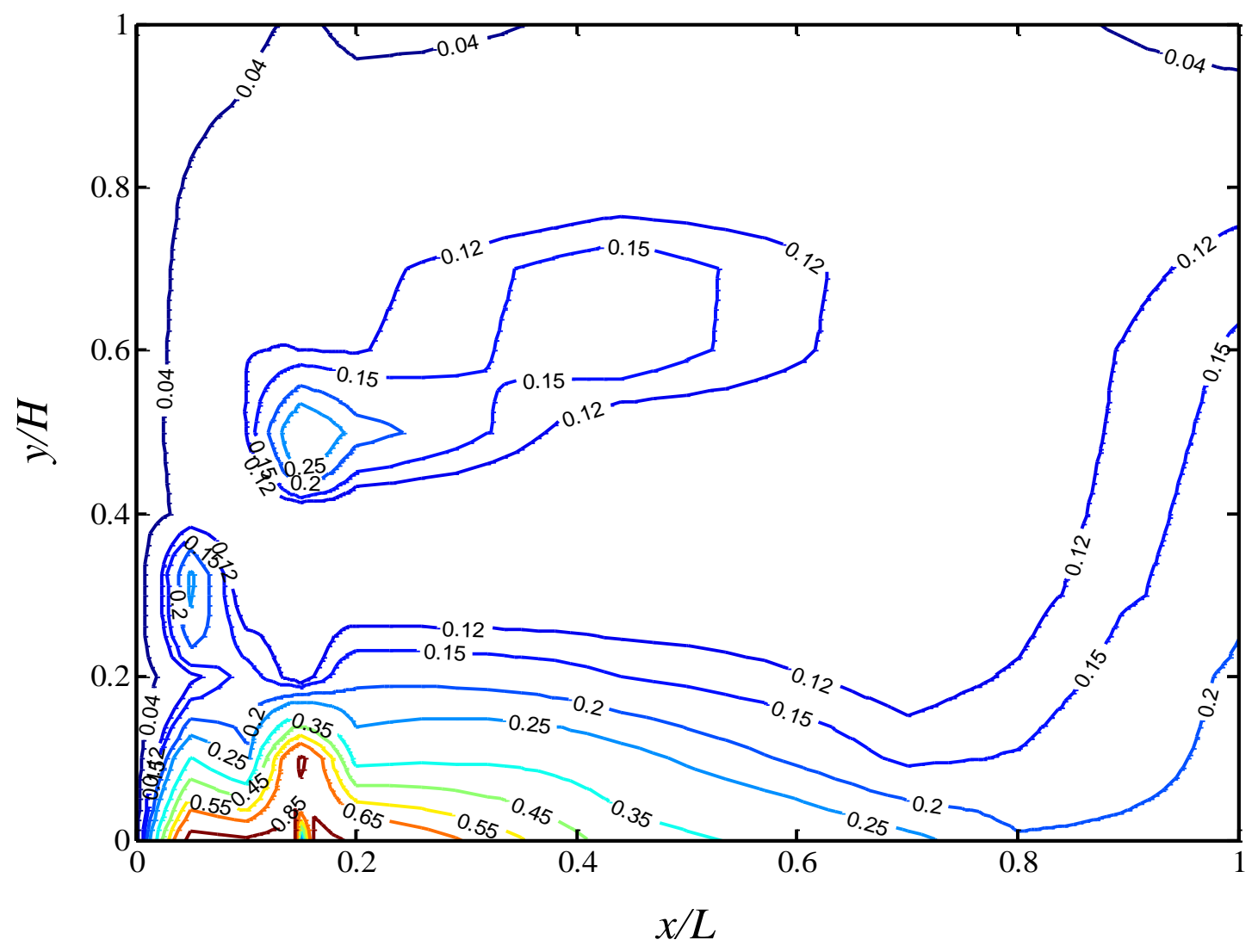

Fig. 7 


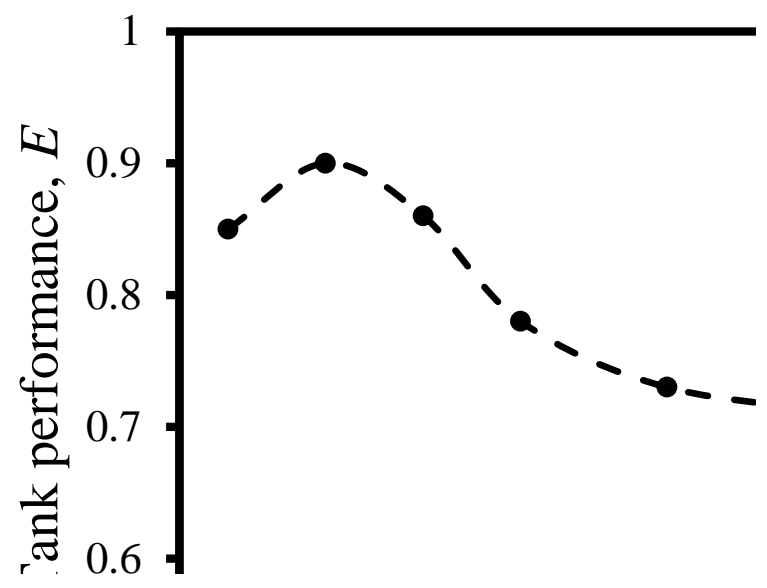

(a)

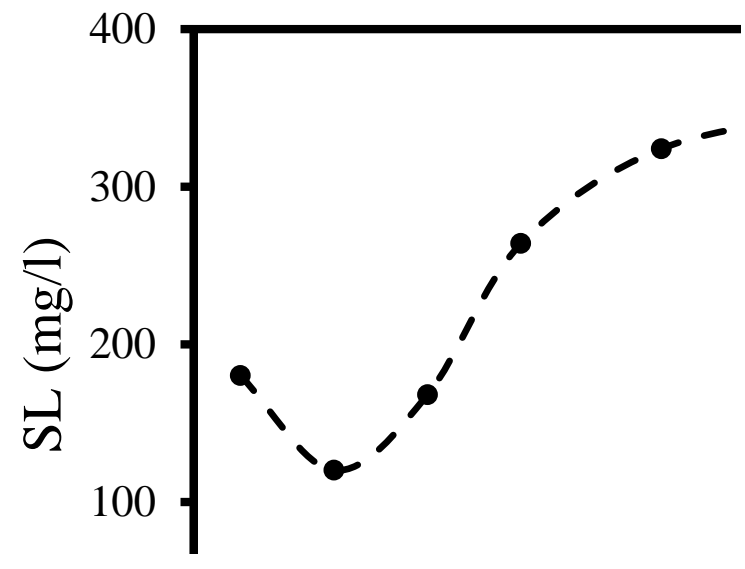

(b)

Fig. 8 


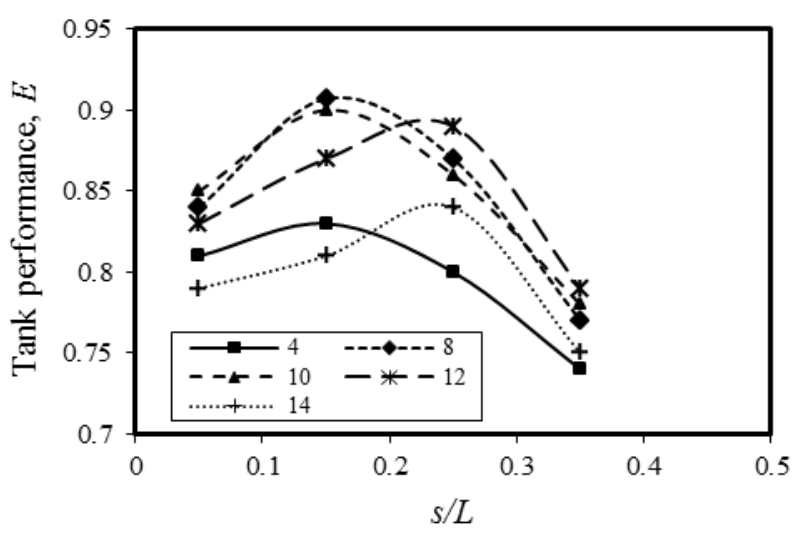

(a)

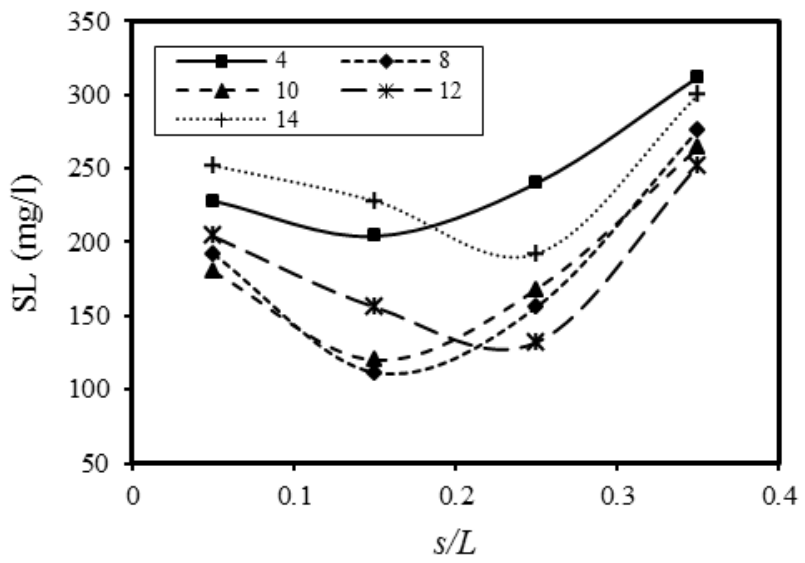

(c)

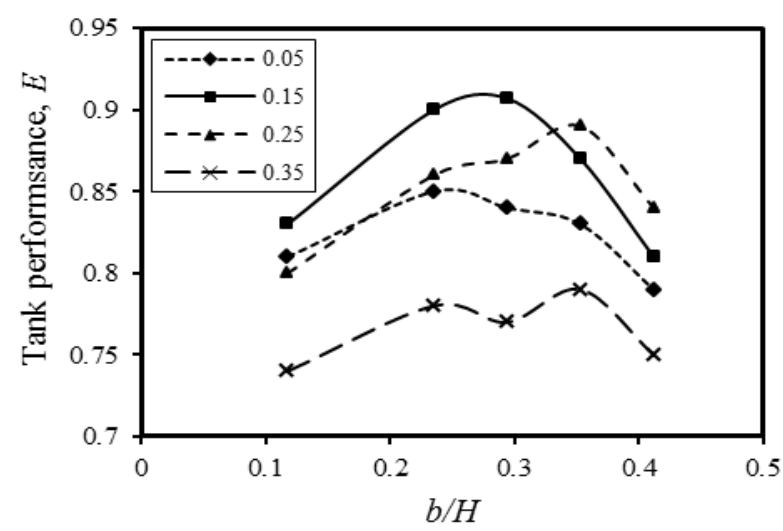

(b)

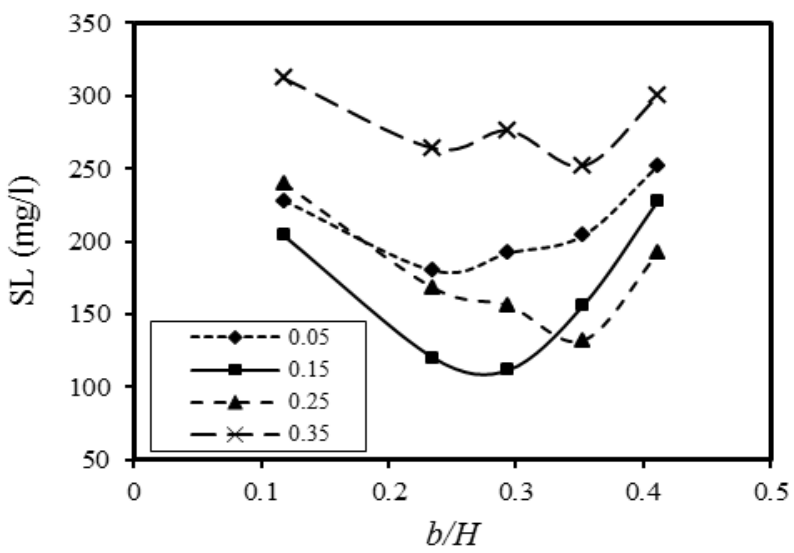

(d)

Fig. 9 